\title{
Explaining Solidarity Through Metaphors: Two Examples From a Romanian Textbook ${ }^{1}$
}

\author{
Elena Negrea-Busuioc (National University of Political Studies \\ and Public Administration Bucharest)
}

\begin{abstract}
:
Solidarity is a complex, abstract, multifaceted concept that may be unpacked and used in a variety of situations, ranging from socio-economic and political contexts to the currently salient pandemic context. Defining solidarity, either in theory or in practice, requires connections to other less abstract ideas, which are more familiar to people. In this paper, I examine the way in which the concept of solidarity is defined and explained in a Romanian social studies textbook for $6^{\text {th }}$ graders. My analysis focuses on two metaphorical framings of solidarity found in the textbook, namely 'solidarity as exchange' and 'solidarity as assistance'. I discuss these examples of metaphors of solidarity in the context of broader discussions surrounding the construction of the intercultural society (of which solidarity is a crucial value) in textbooks.
\end{abstract}

Keywords:

intercultural society; metaphors of solidarity; Romania; social studies textbook

Solidarity is a concept that holds an impressive career both in theory and practice; it is frequently evoked by social and political science scholars, by politicians, activists, etc. in a wide range of scholarly, political, economic, social and, currently very salient, medical and public health contexts. However, it appears that despite (or perhaps because of) its overuse, solidarity is also a misused concept (Scholz, 2008). My aim here is to examine how the concept of solidarity is defined and used in a specific educational context, namely in a Romanian social studies textbook for $6^{\text {th }}$ graders.

Following the fall of the Communist regime, both government and civil society in Romania recognized the need for the Romanian educational system to open up to Europe and the world (Szakács, 2018) by adopting democratic citizenship and intercultural education-related discourses. A key change in the first wave of post-1989 Romanian education reform was the introduction of diversity-sensitive content (Szakács, 2011; Mincu, 2013), which is reflected in the curriculum for a wide range of compulsory and optional disciplines (from history to civic culture). The second post1989 reform was introduced after the passing of the 2010 Education Law. The curriculum for secondary education was changed to include more compulsory subjects that are relevant to citizenship education. For example, the new discipline of social studies was introduced for four years (grades $5^{\text {th }}$ to $8^{\text {th }}$ ) combining previously disparate disciplines of civic culture (compulsory before only for grades 7 and 8) and optional courses such as "intercultural education" (taught before for one year in secondary schools, but only in schools who chose it). Content-wise, the new compulsory discipline of social studies covers key aspects of the role that the individual plays in a democratic society (e.g., human rights and responsibilities $-5^{\text {th }}$ grade, citizenship education $-7^{\text {th }}$ grade, and entrepreneurial education $-8^{\text {th }}$ grade). According to the currently approved curriculum for social studies, the subject of intercultural education is covered in the $6^{\text {th }}$ grade, and includes subtopics and themes such as identity and cultural diversity, principles and values of intercultural society (e.g., diversity and acceptance, tolerance, solidarity, social inclusion, intercultural dialogue, etc.) and intercultural communication.

In this article, I intend to show how solidarity is metaphorically framed in the textbook for social studies for $6^{\text {th }}$ graders and to discuss entailments that the identified metaphors might have in the context of some of the established scholarly approaches to solidarity. A highly desirable value, an expected attitude and a praised sentiment, solidarity is not an innate human trait, people are not born with a solidarity gene, but it is a disposition, a virtue, some may say, that individuals may acquire through education and learning.

Solidarity as Exchange in an Intercultural Society

Undoubtedly, teaching abstract concepts such as 'solidarity', 'diversity', or 'interculturality' to 6th-grade pupils is not an easy task. However, using metaphors to define and explain such abstract notions might help the pupils better grasp their 
meaning and consequently better use such concepts in relation to one another. Metaphors are frequently used in educational discourse to define and explain new and complex ideas (Cameron, 2003; Low, 2005, 2008). Metaphors help simplify abstract ideas by means of foregrounding analogies with concrete, more tangible concepts; at the same time, metaphors facilitate communication by enabling students to make connections between what they already know (existing knowledge) and unfamiliar concepts. In what follows, two metaphors used in a social studies textbook to define and explain solidarity will be analyzed. My analysis focuses on the way in which solidarity is rendered metaphorically in terms of something else, namely as exchange and as assistance, respectively. Furthermore, the two metaphorical framings identified in the textbook are discussed against the background of established scholarly approaches to solidarity. It is worth mentioning, however, that my analysis of the two metaphors of solidarity does not entail assumptions about children's understanding, interpretation and use of these metaphors, i.e. if and how they understand the two metaphors identified here, and whether they are likely to acquire a disposition to feel and exercise solidarity with others.

The focus of the analyzed textbook (Bratu et al., 2018) is on intercultural society. All the lessons and the abstract ideas contained in them revolve around the encompassing notion of intercultural society, which is conveyed as the desirable aim of any modern society. Solidarity together with culture, cultural identity, diversity, intercultural communication, human rights or global citizenship are essential components (values, principles) of the intercultural society. In the textbook, solidarity is discussed in relation to an intercultural society that "celebrates diversity and cultural differences" (Bratu et al., 2018, p. 56). As found in civic education textbooks from England and France (Soysal, 2011) here, too, diversity, especially cultural diversity, is rendered as a precious treasure, 'a treasure' to be sought for in order to enrich an otherwise gloomy world. Culture is metaphorically rendered in terms of an 'iceberg' where only some parts of the whole are visible while others (the vast majority) are invisible (Bratu et al., 2018, p. 11). Furthermore, cultural diversity is a 'puzzle' (Bratu et al., 2018, p. 30) whose distinctly sized and colored pieces are what unite or distinguish people in an intercultural society. Social cohesion in an intercultural society of the type described in the textbook is thus built up by solidarity among people belonging to different cultures, sharing different values and norms, having different lifestyles. Solidarity in an intercultural society is metaphorically defined as an 'exchange' (Bratu et al., 2018, p. 56) between different cultures based on reciprocity and cooperation. The metaphor is extended to explain how student exchange programs and cultural exchange experiences forge solidarity with different people and groups by means of increasing trust in those who look, speak, think and live differently than we do. In this case, solidarity describes a relationship between peers, between people of equal standing (at least from a cultural point of view), where all participants bring something to the table. The 'exchange' metaphor makes it possible to conceive of solidarity as a balanced relationship between individuals and groups in an intercultural society. Similar to a trade partnership, 'solidarity as exchange' shifts the focus from the parties involved in the exchange and their particular characteristics (including physical, ethnic, cultural) onto the output of the exchange. The metaphor highlights the outcome of the relationship, the satisfaction of expectations held by both parties involved in the exchange; entering an exchangebased solidarity relationship, different people, sharing different values and ideals, holding different perspectives of the world may improve their self-awareness and personal development skills, they may stimulate their creativity and increase their trust in themselves and in others (Bratu et al., 2018, p. 57).

'Solidarity as exchange' can be viewed as a choice motivated by the interest of both sides participating in the exchange to create a relationship through which they may grow individually and collectively. Arguably, this metaphorical framing favors an understanding of solidarity as celebrating difference and interdependency. The 'exchange' is less economic than cultural and interpersonal. The 'what's in it for me' type of logic of solidarity is taken over by another logic of the form 'what can we get out of this', in which both parties experience a sense of both personal and collective enrichment as a result of exercising solidarity. In this sense, solidarity is something more than a form of unity between individuals and/or between groups based on similarities in characteristics and rational assessments of self-interest (Bayertz, 1999; Scholz, 2008). As an exchange, solidarity could be seen as a win-win situation, an ad-hoc partnership beneficial to all parties involved and in which what is achieved is more valuable than the different inputs of the individuals participating in the exchange. The circle of solidarity is continuously enlarged to include more diverse people exchanging values, norms, experiences - this is how the foundations of the intercultural society are consolidated.

\section{Solidarity as (Mutual) Assistance}

On the same page (Bratu et al., 2018, p. 56) where solidarity is metaphorically conveyed as exchange, the analyzed textbook defines solidarity as '(mutual)' assistance', too. The metaphor 'solidarity as (mutual) assistance' emphasizes the moral dimension of solidarity that many scholars invoke (Bayertz, 1999; Stjernø, 2005; Scholz, 2008). People's urge to help others seems to be based on moral commitments grounded on shared values and norms, and their acts of solidarity imply some sense of moral obligation towards others. Similar to the example discussed above, the metaphor of 'assistance' points out to a reading of solidarity as unity in difference rather than in similarity. Contrary to 'solidarity as exchange', 'solidarity as assistance' favors an unbalanced relationship between people who are not on an equal footing, namely between the helper and the needy (i.e. vertical 
solidarity). This metaphorical framing is also contained in the very meaning of the word 'assistance'. People in a higher-up position assist (have the responsibility to help) disadvantaged people throughout difficult times; they endorse the moral principle of helping others in need. Vertical solidarity of the kind conveyed by the metaphor of 'solidarity as assistance' is, at a given moment, both unidirectional and circumstantial. Like the metaphor of 'solidarity as exchange', 'solidarity as (mutual) assistance' also builds up trust among different people and groups. When in need, people receive help from those who can assist them and, once their needs met, the once needy may reciprocate the act of solidarity towards others who need it (Bratu et al., 2018, p. 56). To a certain extent, 'solidarity as assistance' resembles 'solidarity as salvation' (Chouliaraki, 2013) since both are informed by a moral sentiment of doing good, of being altruistic.

However, unlike 'solidarity as salvation', which has been criticized of "perpetuating the very suffering it sets out to comfort" (Chouliaraki, 2013, p. 11), as described in the analyzed textbook, 'solidarity as (mutual) assistance' enables the possibility of empowering the receiver of the help to transcend their condition and perhaps help others in their turn. The metaphorical framing of solidarity as assistance foregrounds the humanitarian aspect of solidarity; helping others in need, vulnerable communities "can change the world for the better, so that a single community is built, a community of a humanity that embraces and celebrates diversity and cultural differences" (Bratu et al., 2018, p. 56). 'Solidarity as assistance' is premised on the helper's willingness to selflessly assist others who see the world differently than him/herself while showing care and respect for their culture and traditions. Young people can learn and practice solidarity by getting involved in the European Solidarity Corps projects aimed at building a "community based on shared responsibilities and mutual assistance" (Bratu et al., 2018, p. 56). Conversely, lack of assistance may lead to lack of solidarity, which translates into marginalization, exclusion, isolation (Bratu et al., 2018, p. 57 ) that erode the very foundation of an intercultural society. Marginalization and exclusion will exacerbate the vulnerability of disadvantaged people and groups, reinforcing their sense of powerlessness in a society in which they lack access to services (e.g. welfare, education, health, etc.). Understanding (and performing) solidarity as assistance paves the way for an intercultural society to help vulnerable people move out of their condition.

\section{Implications for Discussions of Solidarity and Intercultural Society in Textbooks}

While politics of inclusion are widely embraced in Europe, the Romanian education system has been urged to rethink educational strategies and policies to include a curriculum on citizenship and intercultural education. The social studies textbook (Educație socială, in Romanian) for the $6^{\text {th }}$ grade, from which the two examples discussed here were taken, reflects the preoccupation for this type of education. Young students aged 11-12 years have thus been introduced, via textbooks, to abstract concepts of intercultural education such as diversity, solidarity, social cohesion, ethnicity, inclusion, marginalization, exclusion, intercultural society, multicultural society. However, representations of diversity in textbooks and other educational media have been criticized for conveying an abstract, superficial, unbalanced, 'unreal' view of a culturally diverse Romania (Szakács, 2011; Mincu, 2013). Despite being given significant space and attention in textbooks, diversity seems to be symbolically rather than substantially manifest in the Romanian schooled context (Szakács, 2011, 2018).

Unlike diversity, solidarity has received little attention in previous studies of Romanian textbook discourse. Nonetheless, solidarity is the cornerstone of any intercultural society and it is a fundamental value upon which the European Union is built (St. John, 2021). Defining solidarity seems to be less problematic than defining diversity, partially because one can more easily find concrete, familiar actions whose attributes can be mapped onto solidarity. The explanatory power of the two metaphors discussed above resides in their capacity to show to pupils how solidarity is a beneficial partnership ('solidarity as exchange') and a morally sound humanitarian gesture ('solidarity as assistance') by appealing to their preexisting knowledge of economic exchanges and altruistic deeds. Furthermore, the metaphorical renderings of solidarity in terms of exchange and assistance favor a pragmatic, more practical understanding of solidarity, which may positively influence the explanation of this abstract idea to pupils in more accessible language. The textbook discourse of solidarity reflects a predilection to define this concept at the individual level - a motivated choice given the age and experience of the target - focusing on how acting in solidarity with others (either in terms of exchange or assistance) may be pragmatically and morally rewarding for the individual. The two metaphors point to a view of solidarity based on cooperation, reciprocity, help, risk sharing and trust. Some scholars consider these to be the attributes of a 'real' solidarity as opposed to 'artificial solidarity' (St. John, 2021), the latter being displayed only when convenient and economically advantageous.

Solidarity is not an innate human characteristic but one that can develop in a nurturing environment (e.g. family, school, community). It is also an abstract concept that can be taught and learnt in school, and metaphors, such as the two examples discussed here, can be used to help simplify the concept and communicate about solidarity to young learners. Solidarity is also a 'public disposition' (Chouliaraki, 2013) informed by the "communicative structure of humanitarianism" (Chouliaraki, 2013, p. 172) and cultivated by educational discourses of care and responsibility. In this context, reflecting on metaphorical framings of solidarity as exchange and assistance may contribute to the debate over 
the nature and uses of solidarity, particularly of solidarity as

a means to (re)imagine human relationships.

\section{References}

Bayertz, K. (1999). Four uses of “solidarity”. In K. Bayertz (Ed.), Solidarity (pp. 3-28). Springer. https://doi.org/10.1007/978-94-015-9245-1_1

Bratu, V., Bratu, A., \& Lupsa, E. (2018). Educatie sociala. Manual pentru clasa a 6-a. [Social studies. Textbook for the 6th grade]. Editura Didactica si Pedagogica.

Cameron, L. (2003). Metaphor in educational discourse. Continuum.

Chouliaraki, L. (2013). The ironic spectator. Solidarity in the age of post-humanitarianism. Polity Press.

Low, G. (2005). Explaining evolution: the use of animacy in an example of semi-formal science writing. Language and Literature, 14(2), 129-148. https://doi.org/10.1177/0963947005051285

Low, G. (2008). Metaphor and education. In R. Gibbs, Jr. (Ed.), The Cambridge handbook of metaphor and thought (pp. 212-231). Cambridge University Press.

Mincu, M. (2013). Balancing citizenship and interculturalism: a comparison of two European contexts of inclusion. Intercultural Education, 24(6), 521-531. https://doi.org/10.1080/14675986.2013.864872

Scholz, S. (2008). Political solidarity. The Pennsylvania State University Press.

Soysal, Y. N. (2011). "Cosmopolitization" of the nation and citizen: European Dilemmas. Berkeley Journal of Sociology, 55, 4-13.

Stjernø, S. (2005). Solidarity in Europe: The history of an idea. Cambridge University Press.

St. John, K. S. (2021). Education and solidarity in the European Union: Europe's lost spirit. Springer Nature.

Szakács, S. (2011). Old wine into new bottles? Europeanization and diversity in multi-ethnic Romanian schools. Multicultural Education Review, 3(1), 99-127. https://doi.org/10.1080/2005615X.2011.11102881

Szakács, S. (2018). Europe in the classroom: World culture and nation-building in post-socialist Romania. Palgrave Macmillan.

\section{Recommended Citation}

Negrea-Busuioc, E. (2021). Explaining solidarity through metaphors: two examples from a Romanian textbook.

On Education. Journal for Research and Debate, 4(10). https://doi.org/10.17899/on_ed.2021.10.9

\section{About the Author}

Elena Negrea-Busuioc is an Associate Professor at the Department of Communication, National University of Political Studies and Public Administration (Bucharest, Romania). Her research interests revolve around the figurative language use in communication (with a focus on metaphor and irony), visual communication and discourse analysis (especially EU-related discourse). She is currently involved in a research project whose goal is to examine the role played by metaphors in the simplification and communication of abstract scientific concepts to young learners.

\footnotetext{
${ }^{1}$ This work was supported by a grant of the Romanian Ministry of Research and Innovation, CNCS - UEFISCDI, project number PN-III-P1-1.1-MCT-20190048, within PNCDI III.
} 